\title{
Schmetterlinge aus aller Welt bereichern die Flugshow
}

\author{
Hilke Steinecke
}

Auch in der vergangenen Wintersaison konnten Besucherinnen und Besucher des Palmengartens in der Flugshow verschiedene exotische Schmetterlinge in tropisch heiß-feuchter Umgebung bewundern. Die Schmetterlinge stammten aus verschiedenen tropischen Gebieten Afrikas, Südamerikas, Südostasiens sowie Australiens. Jede Woche traf ein Päckchen mit Puppen im Palmengarten ein. Da die Artenzusammensetzung bei jeder Sendung etwas variierte, bot die Flugshow immer wieder neue Überraschungen.

Besonders markant ist der Neon-Schwalbenschwanz (Papilio palinurus) aus Indonesien und Südasien. Er gehört zur Gruppe der Achiliden, den am stärksten glitzernden Schwalbenschwänzen. Ihre Flügel schillern meist metallisch grün oder blau. Es gibt vier Unterarten des Neon-Schwalbenschwanzes. Seine Flügelspannweite beträgt bis $8 \mathrm{~cm}$. Die Raupen fressen die Blätter von Citrus-Arten.
Der Gelbrand-Schwalbenschwanz (Papilio lowii) gehört zu den vielen dunkel gefärbten Papilio-Arten. Mit einer Flügelspannweite bis $11 \mathrm{~cm}$ ist er recht groß. Seine Flügelzeichnung

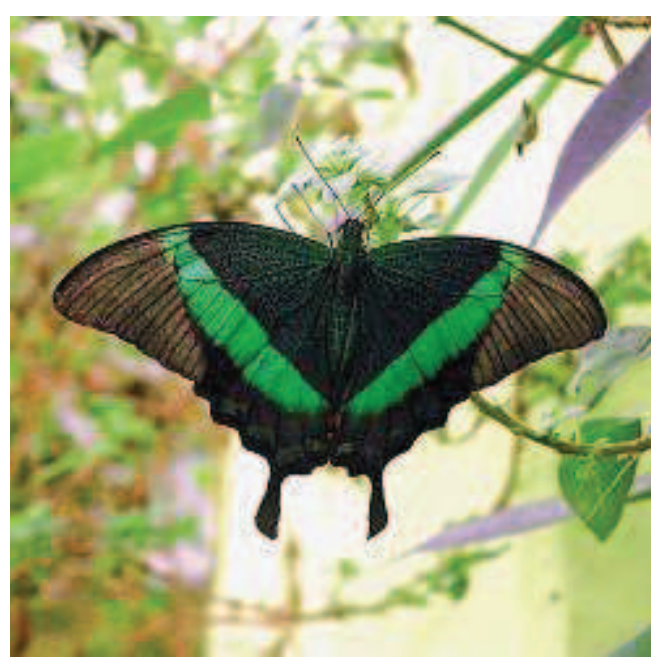

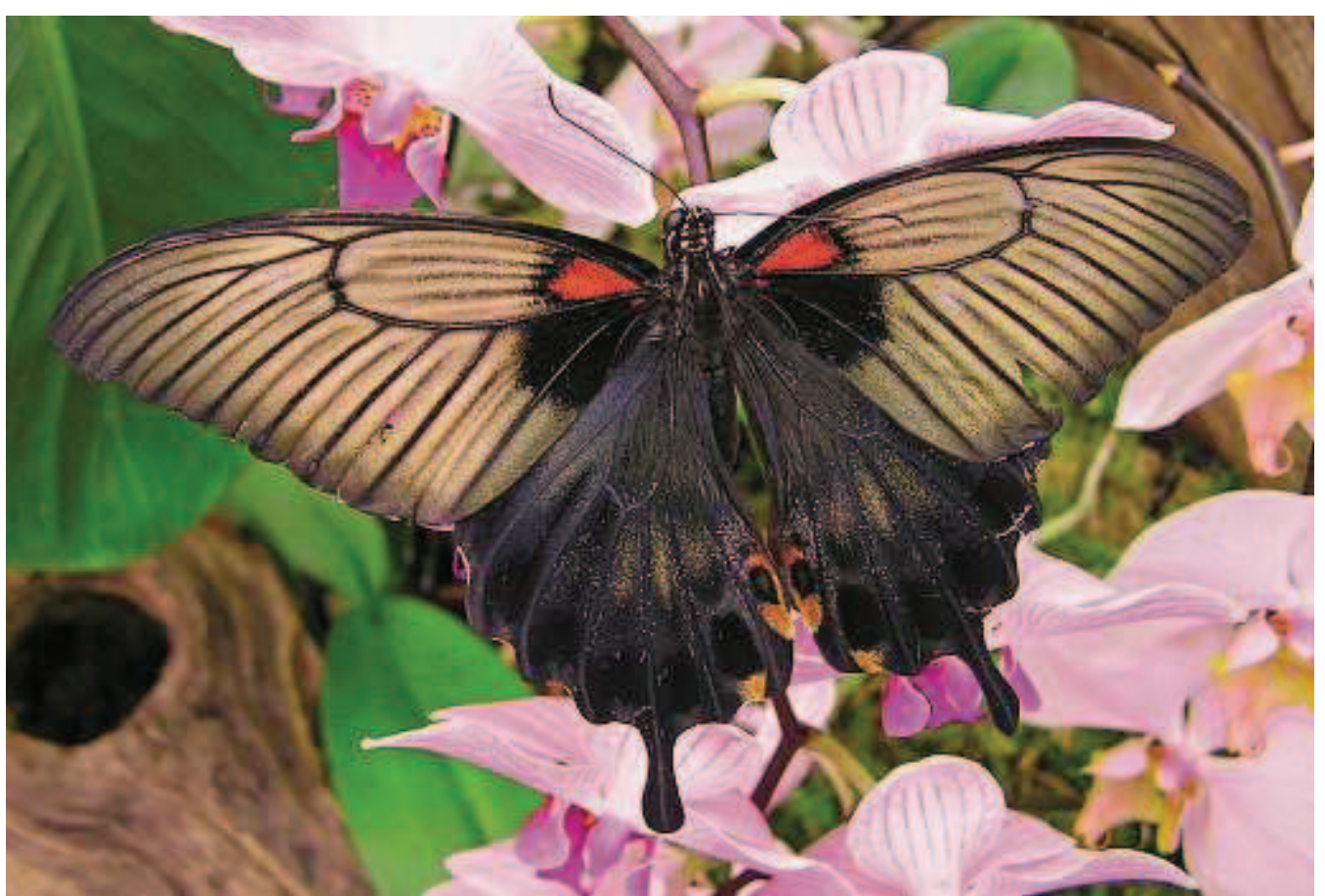



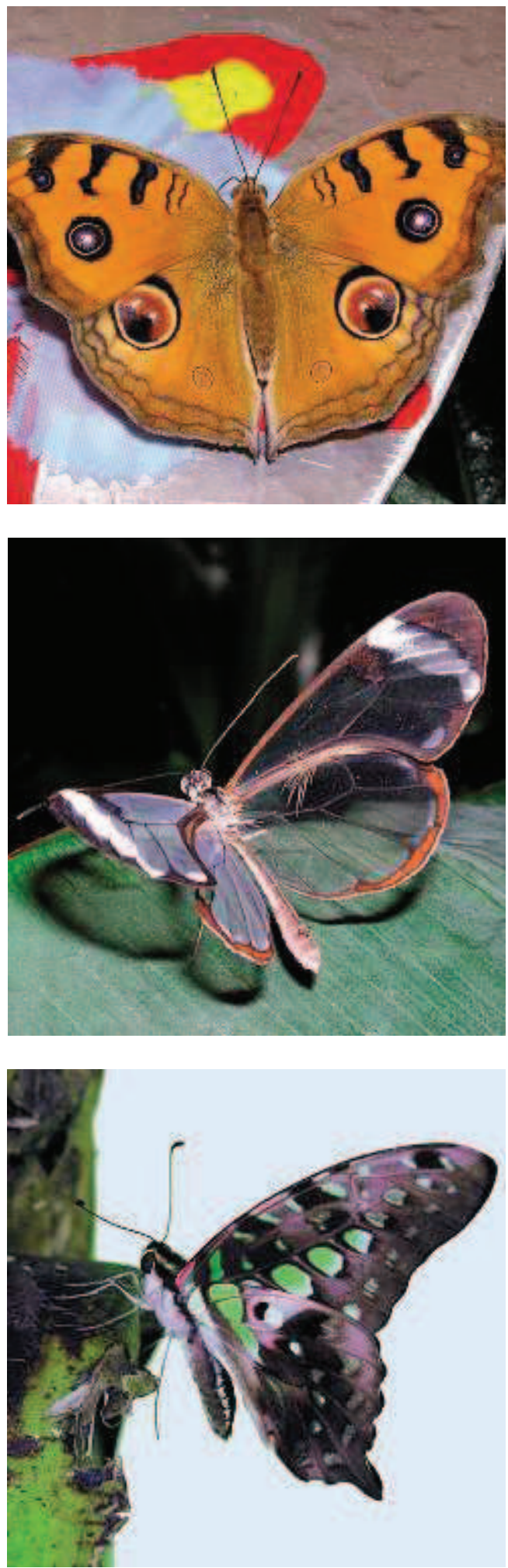

ist variabel und die beiden Geschlechter unterscheiden sich in ihrer Musterung. Er kommt auf der philippinischen Insel Palawan sowie auf Borneo vor. Ähnlich wie unser heimischer Segelfalter kann er im Flug Strecken zurücklegen, ohne dabei die Flügel zu bewegen. Wie bei vielen anderen Schwalbenschwänzen fressen die Raupen Citrus-Blätter.

Precis almana aus Indien ist ein eher etwas kleinerer Tagfalter mit einer Flügelspannweite von nur 5-6 cm. Auf der Oberseite sind seine Flügel leuchtend orange gefärbt, zur Abschreckung von Fraßfeinden haben sie eine Augenzeichnung, die an unser heimisches Tagpfauenauge erinnert. Im zugeklappten Zustand ist der Schmetterling bräunlich gefärbt mit kleinen Augenflecken und ähnelt einem vertrockneten Blatt mit Mittelrippe. Die Gattung Precis kommt weltweit in tropischen Gebieten vor, bevorzugter Lebensraum ist der Regenwald. In der Regenzeit sind die Tiere oft anders gefärbt als in der Trockenzeit. Als Vertreter der Nymphalidae (Edelfalter oder Putzpfotenfalter), zu denen auch Admiral und Distelfalter gezählt werden, hat Precis almana nur 4 Laufbeine, das vordere Beinpaar ist zu Putzpfoten umgewandelt.

Der Glasflügler oder Waldgeist (Greta oto) stammt aus Mexiko und Panama und hat eine Flügelspannweite von nur $3 \mathrm{~cm}$. Da er kaum Schuppen hat, sind seine Flügel größtenteils durchsichtig. Feinde können das Tier deshalb nur schlecht erkennen. Greta oto ist vor allem bei trübem Wetter sowie morgens und abends unterwegs. Die Raupen fressen Blätter des Hammerstrauches (Cestrum).

Der Geschweifte Eichelhäher (Graphium agamemnon) ist im indoaustralischen Raum mit über 20 Unterarten weit verbreitet. Auf der Oberseite ist er auf schwarzem Grund hellgrün gefleckt, so dass er im Flug zwischen belaubten Pflanzen kaum zu erkennen ist. Die Unterseite zeigt auf graubraunem Grund eine zartgrüne Zeichnung. Beide Geschlechter sehen gleich aus. Graphium agamemnon ist ein schneller Flieger. Seine Raupen fressen Blätter von Annona- und Michelia-Arten. 